\title{
Benign cystic adenomatoid malformation: A case report and literature review
}

\author{
Alejandro Hernandez-Solis*, Francisco P. Navarro-Reynoso, and Raúl Cicero-Sabido \\ Pneumology and Chest Surgery, Facultad de Medicina, Universidad Nacional Autónoma de México, Hospital General de México "Dr. Eduardo \\ Liceaga", Mexico City, Mexico
}

\begin{abstract}
Congenital cystic adenomatoid malformation (CCAM) is a benign lung lesion whose incidence is low. The disease can manifest itself right after birth. In some cases, CCAM manifests itself during adolescence or adulthood. This report is about an adolescent patient presented with symptoms of chronic suppurative lung disease, who underwent right lower lobectomy, remaining asymptomatic. These cases are always rectified by means of surgery and patients generally have a good recovery. We have seen the association of this malformation with alterations in other apparatuses and systems.
\end{abstract}

Key words: Congenital cystic adenomatoid malformation. Chronic suppurative lung disease. Lower lobectomy.

\section{Introduction}

Congenital cystic adenomatoid malformation (CCAM) is a condition with different clinical presentations and is sometimes a little symptomatic. It occurs when bronchial dilations become infected or bleed. Among its characteristics, abnormal dilation of the airways with mucous cell proliferation stands out, leading to the appearance of cysts ${ }^{1}$. Given their congenital origin, some symptoms can appear during gestation, in the $1^{\text {st }} \mathrm{h}$ after birth and the first 2 years of life. In the pre-school stage, it manifests itself by repeated infections; thus, the differential diagnosis must be made to rule out bronchiectasis or other suppurative lung diseases ${ }^{2-4}$; in some cases, the presentation may take place later ${ }^{5}{ }^{5}$. This alteration of lung development was initially described by Civin and Tang in 1949, who observed certain pseudoglandular lung developments in stillbirths and premature newborns with hydrops, which refers to generalized subcutaneous edema with an accumulation of fluid in pulmonary cavities ${ }^{1,6}$.

\section{Clinical case}

A 19-year-old male patient with the genetic load by maternal inheritance for diabetes mellitus and systemic hypertension, smoker since the age of 15 , at a rate of five cigarettes/day, who denied having any chronic degenerative diseases.

His condition began 2 months before admission, with unchecked fever, mostly in the mornings, which was partially subsided by the administration of oral antipyretics, with worsening of his overall condition, as well as coughing fits with purulent sputum. The patient received antimicrobial-based medical treatment, presenting no fever 3 weeks after the treatment onset. Subsequently, the patient began with pleuritic chest pain in the right hemithorax of moderate intensity. Hence, chest radiography was performed, where three cystic images of variable diameters were observed.

In the physical examination of the right hemithorax, there was a decrease in vocal vibrations, minor dull, or thud-like lung sounds and a decrease in respiratory

\section{Correspondence:}

${ }^{*}$ Alejandro Hernández-Solis

E-mail: drhernandezsolis@yahoo.com.mx NC-ND license (http://creativecommons.org/licenses/by-nc-nd/4.0/)
Date of reception: 20-06-2019

Date of acceptance: 06-12-2019

DOI: 10.24875/HGMX.19000042
Available online: 21-07-2020 Rev Med Hosp Gen Mex. 2020;83(3):127-130 www.hospitalgeneral.mx 
sounds at the interscapular vertebral space in its middle portion, coarse crackles, 92\% saturation in ambient air, and the remainder of his physical examination without alterations. Respiratory function tests within age, sex, weight, and height parameters.

Regarding radiological studies, a cystic image was observed, of approximately $6 \mathrm{~cm}$ in diameter in the right hilar region, heterogeneous opacity of defined edges with some cystic areas, triangular going from the right hilum to the diaphragm with a negative silhouette. The right lateral radiograph shows a radiolucent image with defined edges occupying the posterior region, showing a hydroaeric level in one of the cystic images. The tomographic section shows a well-circumscribed posterior image on the right side, more or less homogeneous with some radiolucent areas, and some cystic images. No vessels within the images or abnormal vessels were observed with the contrast medium.

Clinical and radiological data were presented, and the right lower lobectomy was performed without any surgical contraindications, which was carried out without problems. The presence of cysts with purulent sputum was confirmed, with bronchiolar lung tissue and dilated alveoli, lined with ciliated pseudostratified columnar epithelia, and no malignancy data. The other lung tissues had a normal structure. However, it was decided, due to the patient's age, good previous lung function, and integrity of the remaining parenchyma, to perform the lobectomy (Fig. 1).

The patient's condition improved and was discharged. The patient visited the outpatient clinic for follow-up with a good clinical evolution without presenting any recurrences.

\section{Discussion}

CCAM is a benign lung lesion, in which patients are presented with symptoms since childhood. Conversely, when patients can reach adolescence or adulthood, with this condition being undetected. Patients can present symptoms of respiratory infection, sometimes hemoptysis. These last two conditions make early diagnosis and treatment important, as the infection can affect other areas of the lung, with the development of the chronic pulmonary disease, which can be serious and may lead to greater complications and even death.

CCAM is a sporadic non-hereditary disease associated with genetic syndromes such as trisomy 18 and hereditary renal dysplasia; its pathogenesis is still unknown, apparently, there is a failure in the interaction of the endoderm with the mesoderm, or due to lack of

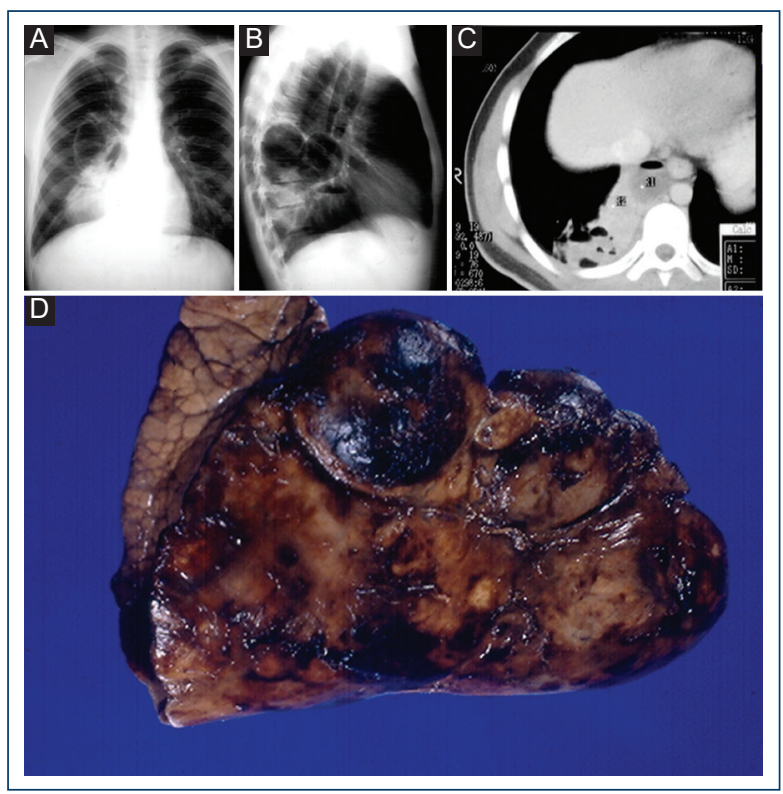

Figure 1. A: chest $\mathrm{X}$-ray with a cystic image of $6 \mathrm{~cm}$ in diameter and heterogeneous opacity of defined edges with cystic zones, going from the hilum to the diaphragm with negative silhouette sign. B: radiolucent image with defined edges in the posterior region and hydroaeric level. C: computed tomography scan shows a posterior circumscribed image on the right side with radiolucent areas and cystic images. D: resected lung lobe, where multiple cystic images of different sizes are observed.

irrigation or an imbalance between cell proliferation and apoptosis during lung development ${ }^{1-3,7}$.

This disease is classified into three types (Table 1). In this study, the patient was an adolescent without respiratory disease history, presenting symptoms 2 months before admission. An X-ray was taken, in which a circumscribed image was observed. Thus, a chest computed tomography (CT) scan was requested, where it was evidenced that the disease was limited to the lower lobe and was a Type I cystic adenomatoid disease. A lower lobectomy was performed, as this procedure ensured good residual lung function, and major complications such as recurrent pneumonia, chronic suppurative lung disease (CSLD), and hemoptysis would be avoided ${ }^{1,2,8,9}$. The calculated loss of lung function from a lobectomy is only $10 \%$, which does not compromise the patient's function. Therefore, without smoking or exposure to other pneumotoxic agents, the patient will lead a normal life ${ }^{10,11}$.

Associated malformations, especially those of Type II, are observed in up to $42 \%$ of patients, such as genitourinary disorders, renal agenesis, and Potter syndrome. Malformations are related to cardiovascular abnormalities 
Table 1. Classification of congenital cystic adenomatoid malformation ${ }^{5,12}$

\begin{tabular}{|l|l|}
\hline Type I & $\begin{array}{l}\text { One or more cysts of } 2 \mathrm{~cm} \text { or more, lined with } \\
\text { ciliated pseudostratified columnar epithelia, } \\
\text { surrounded by elastic tissue, smooth muscle bands, } \\
\text { fibrovascular membranes, and cartilage. Alveoli } \\
\text { with normal characteristics between the cystic } \\
\text { structures. This type corresponds to } 60-70 \% \text { of } \\
\text { cases. }\end{array}$ \\
\hline Type II & $\begin{array}{l}\text { Multiple cysts of uniform size, smaller than } 2 \mathrm{~cm}, \\
\text { with terminal bronchioles of aberrant architecture } \\
\text { between structures similar to large alveoli. They } \\
\text { consist of a columnar or cuboidal epithelial wall } \\
\text { surrounded by a thin fibromuscular layer and rarely } \\
\text { have cartilage. It constitutes } 20 \text { to } 30 \% \text { of the } \\
\text { cases; } 50 \% \text { associated with extra lobar pulmonary } \\
\text { sequestration (ELS). }\end{array}$ \\
\hline Type III & $\begin{array}{l}\text { Voluminous solid mass, consisting of millimeter-like } \\
\text { structures similar to bronchioles, separated by } \\
\text { masses of alveolar type structures of cuboidal } \\
\text { epithelium. It corresponds to } 10 \% \text { of cases. }\end{array}$ \\
\hline
\end{tabular}

in $21 \%$ of patients (persistence of the ductus arteriosus, dextrocardia, and among others), rib cage malformations in $16 \%$ of patients (pectus excavatum), and other malformations in $5 \%$ of patients. These include pyloric stenosis, pulmonary hypoplasia, diaphragmatic hernia, hydrocephalus, jejunal atresia, and Pierre-Robin syndrome that consist of micrognathia and glossoptosis and accompanied by a cleft lip and palate, as well as lesions of the hard and soft palate, high-arched palate, or the presence of hemi-vertebrae $7,12,13$. It is suggested that for cases of adenoid cystic malformation, genitourinary disorders should be investigated due to the possibility of association with alterations at this level $\left.\right|^{12,13}$.

As for the differential diagnosis in children, diseases such as diaphragmatic hernia, where the presence of abdominal viscera is found in the thoracic space, pulmonary sequestration that can be differentiated from CCAM, because pulmonary sequestration receives the blood supply from an accessory artery of the aorta, which can observed by Doppler ultrasound. In addition, bronchogenic cysts that are most commonly located in the mediastinum and carina, and congenital lobar emphysema commonly associated with congenital heart disease. Lesions in children with one or multiple cysts of $5 \mathrm{~mm}$ or more in diameter have a better prognosis, allowing treatment in utero, by means of thoracentesis (fluid aspiration) or lobar resection, which reduces the risk of pulmonary hypoplasia 2,6,9,14. Endobronchial obstructive infections or causes and mass lesions can be completely ruled out by clinical-radiological findings or by bronchoscopy ${ }^{2,14}$.
These cases are commonly diagnosed during childhood, as patients are presented with some symptoms from an early age. In the case under study, the patient had symptoms, as reported, up to the age of 19 . Subsequently, the patient remained asymptomatic, a situation that is very significant, as the manifestation of CCAM is more frequent in children under the age of two $0^{6,7}$.

The diagnosis can be supported by imaging studies, which can initially be a diagnostic suspicion, by means of a simple chest $\mathrm{X}$-ray, where a radiolucent image can be seen that may lead to a diagnostic suspicion and rule out other diseases. With this diagnostic suspicion, a chest CT scan should be requested, as it allows a clearer view of the lesions, their extension, the involvement with adjacent structures, and their relationship with the pulmonary and systemic circulation so that the diagnosis can be refined.

A differential diagnosis with radiological imaging in patients is related to cases of patients with giant bronchiectasis, as in some types of bronchiectasis, they tend to form cysts that are histologically different from this disease, but unlike adenomatoid disease, bronchiectasis is a CSLD ${ }^{15}$.

There are reports, in which they have found different types of the disease in the area of the affected lung. However, this does not affect the decision regarding the type of surgical procedure chosen for each case. The lesions in the case under study were confined to a large part of the lower lobe; thus, lower lobectomy was the procedure of choice. Large lesions are associated with hypoplasia of ipsilateral or contralateral lung lobes, and no predilection for a particular site of the lung parenchyma has been described ${ }^{7,16}$.

In our review for the present case, we found few reports regarding the association of adenocarcinoma with the cystic adenomatoid disease. However, in reality, there are so few cases that we cannot say that the latter alone is a risk for cancer ${ }^{9}$. Malignancy of the cystic lesion, leading to rhabdomyosarcoma or pleuropulmonary blastoma, is reported in some cases, which occurs for Type I in $<1 \% 6,8,11$.

\section{Conclusion}

CCAM is a rare pathology that must be taken into account from gestation to birth, as well as being a differential diagnosis for other congenital diseases that affect the chest. Once the diagnosis is made, the possibilities for resolution are high, which will depend on the type of involvement according to its classification. This includes searching for other alterations in other apparatuses and 
systems. Overall, the prognosis is good, and no hereditary pattern has been found. In the reported case, the late onset of the disease was observed in a 19-year-old male patient with a good post-operative evolution.

\section{Conflicts of interest statement}

The authors deny any conflicts of interest related to the preparation of this manuscript.

\section{Ethical disclosures}

Protection of human and animal subjects. The authors declare that no experiments were performed on humans or animals for this study.

Confidentiality of data. The authors declare that they have followed the protocols of their work center on the publication of patient data.

Right to privacy and informed consent. The authors have obtained the written informed consent of the patients or subjects mentioned in the article. The corresponding author is in possession of this document.

\section{References}

1. Lujan M, Bosque M, Mirapeix RM, Marco MT, Asensio O, Domingo C Late-onset congenital cystic adenomatoid malformation of the lung. Res piration. 2002;69:148-54.
2. Kim W, Lee K, Kim IO, Suh YL, Im JG, Yeon KM, et al. Congenital cystic adenomatoid malformation of the lung: CT-pathologic correlation. AJR. 1997;168:47-53.

3. Hulnick D, Naidich D, McCauley D, Feiner H, Avitabile A, Greco M, et al. Late presentation of congenital cystic adenomatoid malformation of the lung. Radiology. 1984;151:569-73.

4. Fibla JJ, Molins L, Mier JM. Malformación adenomatoidea quística pulmonar de afectación bilateral en el adulto. Arch Bronconeumol. 2008;44:226-7.

5. Congregado M, Loscertales J, Girón-Arjona JC, Jiménez-Merchán R Arroyo-Tristán A, Cámpora RG. Tres casos de malformación adenomatoidea quística en el adulto tratados por cirugía videotoracoscópica. Arch Bronconeumol. 2004;40:236-9.

6. Mata J, Cáceres J, Lucaya J, García-Conesa J. CT of congenital malformations of the lung. Radiographics. 1990;10:651-74

7. Oh BJ, Lee JS, Kim S, Lim M, Koh Y. Congenital cystic adenomatoid malformation of the lung in adults: clinical and CT evaluation of seven patients. Respirology. 2006;11:496-501.

8. Rosado M, Stoker J. From the archives of the AFIP. Congenital cystic adenomatoid malformation. Radiographics. 1991;11:865-86.

9. Ioachimescu C, Mehta C. From cystic pulmonary airway malformation, to bronchioloalveolar carcinoma andeno-carcinoma of the lung. Eur Respir J. 2005;26:1181-7.

10. Mondragón J, Jiménez R, Alvarado R, Gallego J, Galicia A. Malformación adenomatoidea quística pulmonar. Informe de un caso de presentación tardía. Acta Pediatr Mex. 2004;25:333-6.

11. Escobar LF, Fuentes DF, Urzúa FC, Capetillo FM. Malformación adenoquistica pulmonar de presentación tardía. Presentación de un caso. Rev Chil Radiol. 2010;16:190-4

12. Antón-Martin P, Cuesta-Rubio MT, López-Gonzalez MF, Ortiz-Movilla R Llorente-Jareño ML, López-Rodríguez E, et al. Malformación adenomatoidea quística congénita. Rev Chil Pediatr. 2011;82:129-36.

13. Reynoso-Argueta E, Hernández-Nájera BA, Barriga-León JJ, Barrera-Martínez I. Malformación adenomatoide quística en un recién nacido. Reporte de un caso y revisión de la literatura. Rev Med Hosp Gen Mex. 2008;71:36-4.

14. Ayed A, Owayed A. Pulmonary resection in infants for congenital pulmonary malformation. Chest. 2003;124:98-101.

15. Navarro-Reynoso FP, Kuthy-Porter J, Cicero-Sabido R. Bronquiectasias gigantes a cuerpo extraño. Neum Cir Tórax. 1989;7:31

16. Ortega-Zhindón DB, Torres-Martínez R, Campos-Badillo A. Malformación adenomatoidea quística, reporte de caso y revisión de la literatura. Neumol Cir Torax. 2018;77:34-7. 